\title{
EFFICENCY : ELECTRIC SMART CHAIR SEBAGAI INTELLIGENT TRANSPORT UNTUK EFISIENSI PENARIKAN TIKET PENUMPANG KERETA
}

\author{
Setya Wahyu Priyadi ${ }^{1}$, Rachmad Hidayat ${ }^{2}$, Koko Joni ${ }^{3}$ \\ Teknik Elektro, Fakultas Teknik \\ Universitas Trunojoyo Madura, Bangkalan, Indonesia \\ e-mail : ${ }^{1}$ setyasetya95@gmail.com, ${ }^{2}$ dr.rachmad.mt@gmail.com, ${ }^{3}$ kokojoni@gmail.com \\ Diterima: 25 September 2018. Disetujui : 5 Desember 2018. Dipublikasikan : 10 Desember 2018 \\ (C)2018 -TESJ Fakultas Teknik Universitas Maarif Hasyim Latif. Ini adalah artikel dengan \\ akses terbuka di bawah lisensi CC BY 4.0 (https://creativecommons.org/licenses/by/4.0/)
}

\begin{abstract}
ABSTRAK
Electric smart chair merupakan suatu alat yang digunakan untuk membantu petugas PT. KAI dalam hal penarikan dan pengecekan tiket penumpang kereta api sehingga waktu penarikan dan pengecekan data sesuai dengan database penumbang terbukti lebih efisien dan valid. Sebagai pengembangan alat ini memanfaatkan konsep intellegent transport system untuk mempermudah perbaikan sebuah sistem. Sistem kerja alat ini memanfaatkan beberapa komponen penting seperti barcode scanner, arduino, motor servo dan lampu LED serta Delphi dan Arduino sebagai perangkat lunak pendukungnya. Sistem kerja alat ini dimulai dari penumpang memesan tiket kereta dengan memasukan input nama, NIK KTP dan tujuan untuk mencetak tiket. Selanjutnya penumpang pergi ke stasiun tujuan untuk pemberangkatan. Pada pintu masuk gerbong kereta api, setiap penumpang wajib melakukan verifikasi data tiket dengan menunjukan tiket yang telah dicetak tadi ke barcode scanner. Jika data terverifikasi dengan benar, maka secara otomatis data tersebut memerintahkan untuk membuka kursi ditandai dengan notifikasi nyala lampu $L E D$ berwarna hijau. Motor servo sebagai pengerak kursi dengan sudut $90^{\circ}$. Jika data tidak terverifikasi dengan benar, maka kursi tidak akan terbuka. Sehingga memungkinkan tidak adanya penumpang yang ilegal, penumpang duduk sesuai nomor kursi yang telah dipesan, dan jumlah penumpang tidak melebihi batas. Selanjutnya, jika penumpang sudah sampai ditempat tujuan setelah 10 menit penumpang turun secara otomatis tempat duduk tadi akan tertutup sendiri.
\end{abstract}

Kata kunci: arduino, barcode scanner, efisien, intellegent transport system, kereta, motor servo

\section{PENDAHULUAN}

Di Indonesia, peran dari kereta api dirasa masih kurang maksimal. Salah satu faktor penyebab adalah penggunaan teknologi dalam bidang perkeretaapian yang masih kurang dibandingkan dengan moda transportasi darat lainya. Berdasarkan catatan Badan Pusat Statistik (BPS) sepanjang Mei 2017 jumlah penumpang kereta mencapai 33,75 juta penumpang naik cukup signifikan termasuk kereta Jabodetabek atau KRL. Besarnya komponen biaya transportasi kereta api disebabkan oleh kurang efisiennya satu atau lebih elemen dari sistem transportasi. Efisiensi memiliki tolok ukur seperti pemanfaatan sumber daya, biaya operasi, nilai waktu, keselamatan operasi dan sebagainya. Menurut Juliyanto (Juliyanto, 2015) transportasi kereta api terus berusaha melakukan perbaikan yang dianggap kurang dan melakukan perbaikan yang dengan kualitas pelayanan yang sesuai agar dapat menarik minat masyarakat untuk berpindah menggunakan kereta api. PT KAI (Persero) diwajibkan melakukan perbaikan terus- menerus dengan kualitas pelayanan sesuai dengan keinginan konsumen atau masyarakat yang terus menuntut pelayanan yang lebih baik dan dapat mengatasi persaingan dengan transportasi yang lain.

Pada hari Selasa, 03 Oktober 2017 jam 07.40 anjloknya rangkaian KA 1507 Bogor-Angke di dekat Stasiun Manggarai membuat para pengguna KRL menjadi khawatir kejadian serupa bakal terulang lagi. Terlebih, dalam kondisi musim penghujan saat ini. Rel kereta menjadi lebih licin dari biasanya (Rahayu, 2017). Selain kekhawatiran itu, Endah juga mengomentari kapasitas penumpang kereta api. Terkadang, sampai overload hingga kondisi di dalam kereta pengap. Hal ini perlu dipikirkan agar tidak menjadi salah satu alasan jika kejadian serupa terulang kembali (Infonitas.com). Humas PT KAI Daerah Operasi (DAOP) 1 Bambang Setyo Prayitno memastikan calo tiket kereta api sudah tidak ada. Namun, masalah lainya justru muncul, yakni maraknya aksi penipuan di stasiun kereta api. Model penipuanya banyak yang tidak sesuai dengan identitas 
penumpang atau pemalsu identitas. Bambang mengatakan, kebanyakan kasus justru diketahui saat di perjalanan, ketika tempat duduk di kereta api diperebutkan oleh dua penumpang. Hal inilah yang membuat para penumpang kereta api overload karena masih banyak diwarnai kecurangan.(Agmasari, 2016)

Secara umum penelitian terhadap adanya permasalahan pelayanan penumpang pada kereta api dapat dilakuan dengan memunculkan inovasi baru melalui teknologi sebagai pendukung intelligent transportation system. dengan menggunakan perangkat scanning barcode, dimana sistem akan bekerja apabila menerima gambar barcode yang databasenya sudah di inputkan di pusat untuk memverifikasi penumpang dan mencegah kecurangan pada penumpang. sehingga peneliti mengusulkan skripsi dengan judul efficiency : electric smart chair sebagai intelligent transport system untuk efisiensi penarikan tiket penumpang dan mitigasi overload passenger pada kereta api.

\section{METODE PENELITIAN}

\section{Pengumpulan Informasi}

Mengumpulkan informasi dari berbagai sumber yang terpercaya untuk merumuskan pemunculan ide pembuatan alat ini sebagai problem solving sistem perkeretaapian. Kepastian informasi ini akan dikumpulkan untuk mempermudah dan memungkinkan diterapkannya Electric Smart Chair sejak dini untuk memperbaiki sistem.

\section{Studi literatur dan Riset Perangkat}

Dilakukan analisis karakteristik kerja dan kesesuaian dari tiap-tiap komponen pendukung ide perancangan sehingga diperoleh rancangan dengan desain sederhana tetapi menghasilkan perangkat yang optimal baik dari segi mekanis, elektronik maupun ergonomisnya dalam pengunaanya.

\section{Perancangan Sistem}

Hasil dari riset perangkat yang telah dievaluasi dari berbagai sudut pandang pemikiran, kemudian dilanjutkan dengan desain sistem yang mencakup desain mekanis, elektronis dan perangkat lunaknya. Setelah proses pendesainan, hal yang dilakukan adalah merancang seluruh komponen hasil pendesainan awal. Pemilihan komponen yang tepat ditinjau dari penggunaan daya yang rendah dan reliabilitas terhadap kondisi lingkungan yang baik serta penerapan komponen pada papan tercetak (PCB).

\section{Pemrograman Pengendali Utama}

Pemrograman pengendali utama adalah hal yang paling penting dalam tahapan pembuatan perangkat ini. Pengendali utama dari perangkat ini menggunakan mikrokontroler arduino yang akan mengelola informasi scanning barcode penumpang dari tiket online (virtual tiket) dan offline. Selanjutnya akan diproses untuk perintah membuka kursi kereta dan notifikasi lampu hijau jika tiket tersebut asli sesuai dengan database server pemesanan.

\section{Simulasi}

Tahapan simulasi hanya bisa dilakukan pada hasil disain elektronis dan pada hasil disain perangkat lunak. Untuk simulasi elektronis menggunakan piranti perangkat lunak Arduino UNO untuk mengatur semua sistem kendali elektronis. Sedangkan untuk pengaturan sistem database digunakan perangkat lunak DELPHI untuk pengaturan sistem pemesanan tiket dan verifikasi tiket kereta api.

\section{Pengujian Sistem dan Alat}

Pengujian sistem secara menyeluruh sebagai tahap terakhir untuk mengetahui kerja dari alat penelitian apakah sudah sesuai dengan yang diharapkan. Kombinasi pola kerja dari alat bisa dicari dengan mengubah perangkat lunak mikrokontroler hingga diperoleh hasil yang terbaik..

\section{HASIL DAN PEMBAHASAN}

Gambar 1 merupakan representasi sistem nyata hasil yang ingin dicapai oleh tim peneliti. Alur berjalannya sistem Electric Smart Chair ini dimulai dari penumpang memesan dan membayar

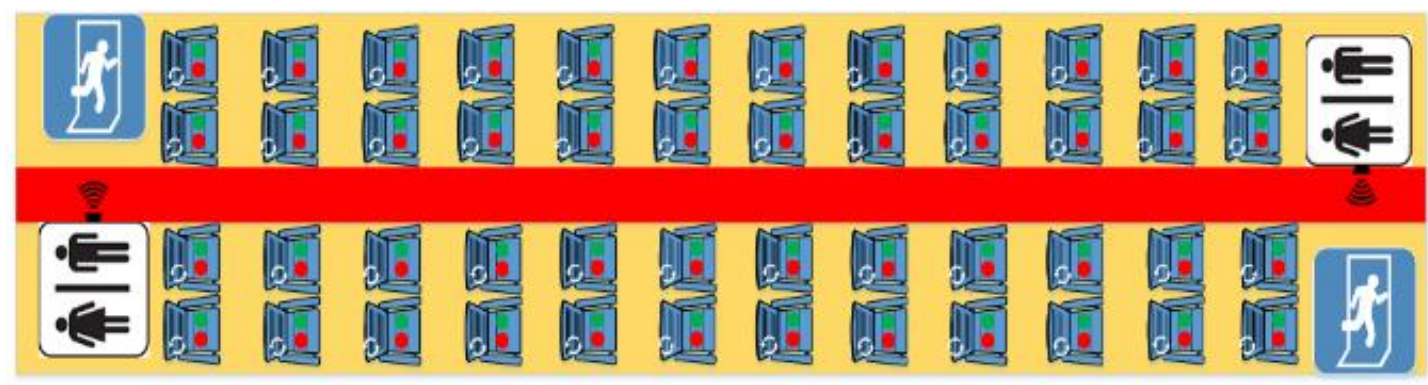

Gambar 1. Rancangan EFFICIENCY 
tiket kereta api via online melalui aplikasi atau offline melalui stasiun kereta api terdekat. Selanjutnya penumpang mencetak tiket kereta atau menyimpan e-ticket di smartphone yang di dalamnya terdapat barcode ID setiap penumpang. Setelah penumpang mendapatkan tiket kemudian setiap penumpang wajib meng-scanning tiap tiket yang barcode scanner yang terlihat pada Gambar 1 yang terletak pada pintu masuk sebelah kamar mandi. Setelah tiket di scaning, apabila terverifikasi sesuai ID pemesanan maka secara otomatis kursi akan terbuka dan memberikan notifikasi berwarna hijau. Selanjutnya penumpang dipersilahkan duduk ditempat menikmati perjalanan. Setelah penumpang sampai pada tempat tujuan sistem akan memberikan toleransi waktu 15 menit untuk persiapan penumpang turun kereta mempersiapkan barang-barangnya. Setelah 15 menit kursi akan secara otomatis tertutup.
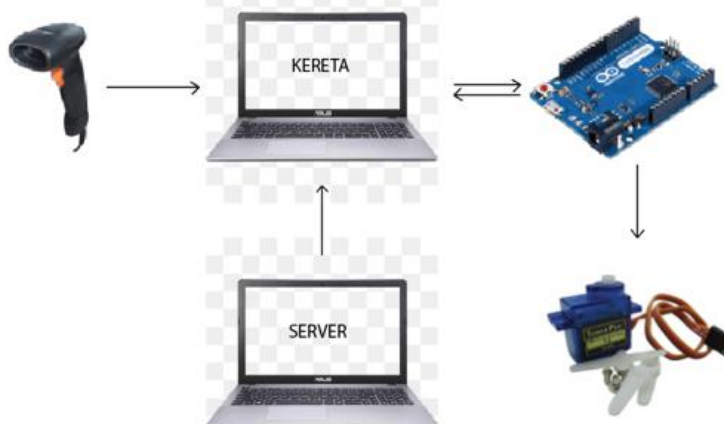

Gambar 2. Rancangan elektronik EFFICIENCY

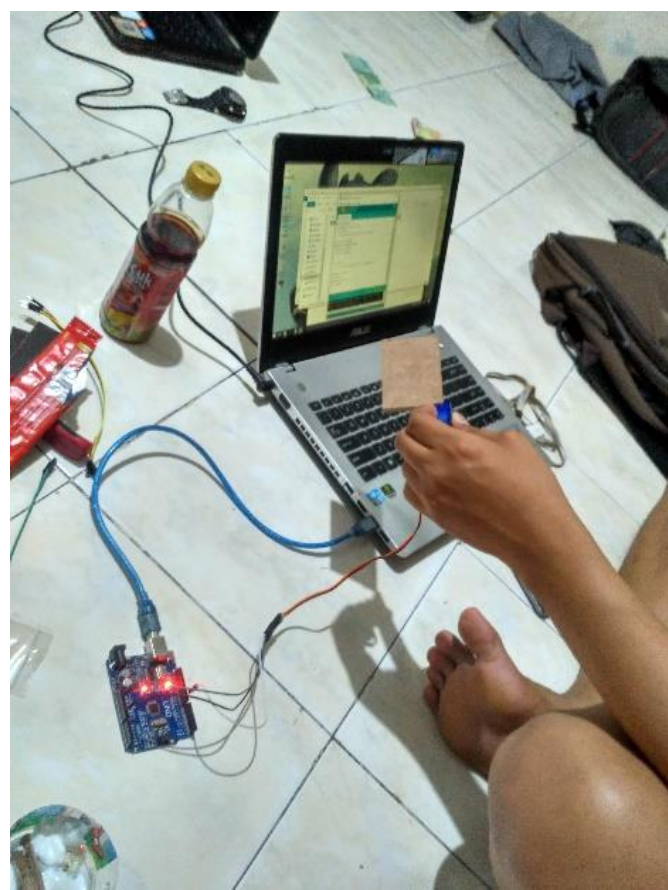

Gambar 3. Uji elektronik dan algoritma

Gambar 2 merupakan desain elektronik. Dengan server sebagai database penumpang PT.
KAI dan komputer kereta sebagai salinan dari database server yang terupdate dengan jaringan wifi lokal yang terupdate setiap kereta berhenti di stasiun dan sebagai verifikator ke-valid-an data penumpang PT. KAI di dalam kereta. Pengerak auto rotate pada kursi dalam penelitian ini menggunakan motor servo yang dapat bergerak 90․ Kemudian led notification menggunakan lampu led kecil sebagai notifikasi pemberitahuan kalau tiket sudah terverifikasi dengan benar.

Trial and eror test dari sistem electric smart chair. Hal ini dilakukan agar sistem yang dibuat telah sesuai dengan gambaran sistem nyata.

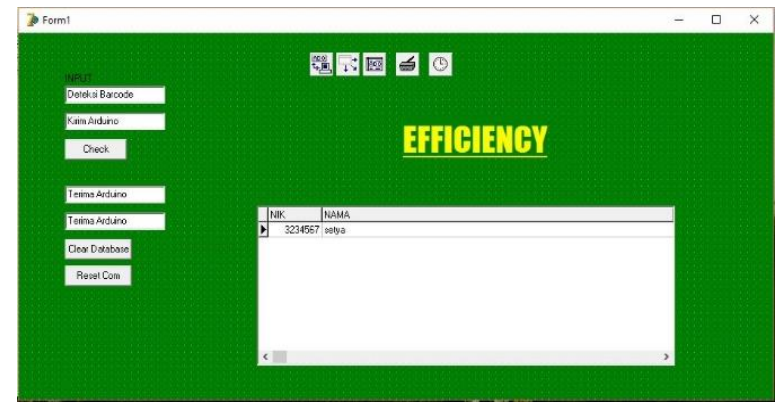

Gambar 4. Tampilan pemesanan tiket (database server)

Gambar 4 marupakan tampilan database dari sistem pemesanan tiket penumpang kereta api dan untuk mencetak barcode tiket penumpang.

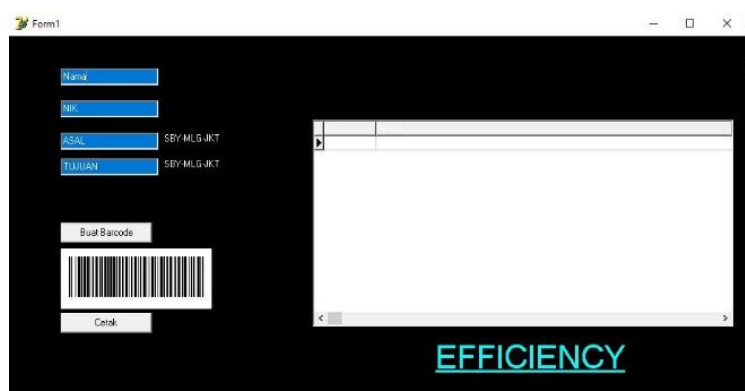

Gambar 5. Tampilan scanning barcode penumpang di dalam kereta

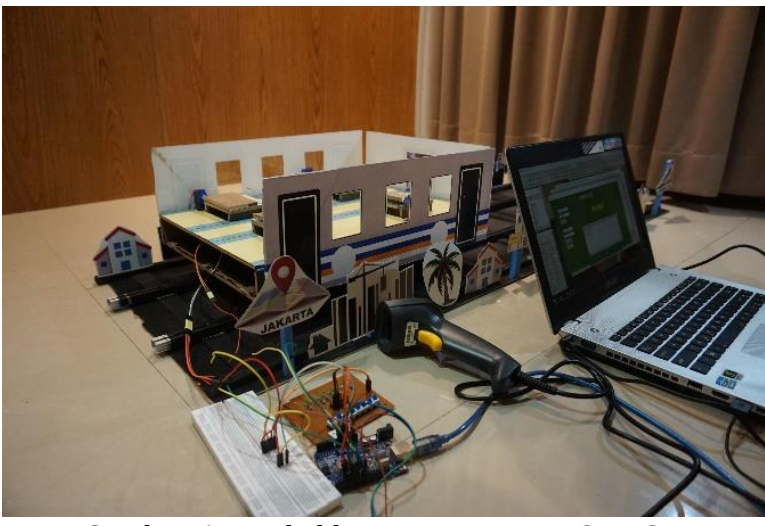

Gambar 6. Hasil akhir prototype EFFICIENCY

Setelah para penumpang memesan dan mencetak tiket kerata api. Setiap penumpang wajib melakukan proses verifikasi tiket pada barcode 
scanner yang telah tersedia di gerbong kereta api. Tampilan diatas merupakan tampilan untuk proses verifikasi barcode pada tiket yang terhubung dengan sistem database pada PT. KAI (server).

Gambar 6 merupakan hasil akhir dari prototype sistem electric smart chair yang telah dibuat. Berdasarkan Gambar 6 tersebut, dari hasil akhir yang telah dibuat terbukti bahwa sistem electric smart chair ini dapat diaplikasikan ke kereta api dengan objek pihak PT. KAI.

Berikut pada Gambar 7 dan Gambar 8, percobaan yang sudah dilakukan untuk input data sebanyak 5 kali ke dalam database Ms. Access.

\begin{tabular}{|l|l|l|}
\hline \multicolumn{2}{|c|}{ Field Name } & \multicolumn{2}{|c|}{ Data Type } \\
\hline NIK & Number & PK \\
\hline NAMA & Short Text & \\
\hline ASAL & Short Text & \\
\hline TUJUAN & Short Text & \\
\hline
\end{tabular}

Gambar 7. Jumlah dan tipe data field database

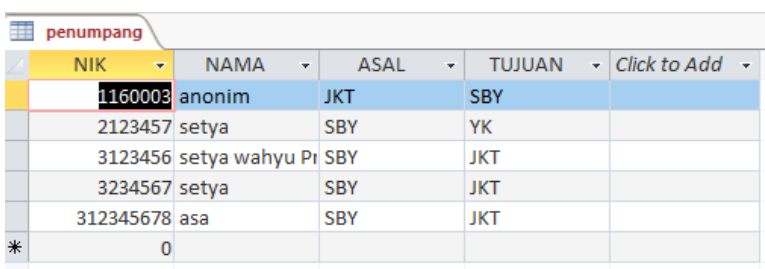

Gambar 8. Uji input database

Dari Gambar 8, dilakukan sebanyak 5 kali percobaan input data penumpang ke database yang berhasil dilakukan dengan NIK sebagai primary key (Gambar 7) dengan NIK sendiri adalah gabungan data NIK dari penumpang dan tujuan penumpang. Pada Gambar 8 tersebut, bisa dianalisa bahwa penulis memberikan kode tujuan pada digit pertama dimana untuk Surabaya adalah "1", Yogyakarta adalah "2", dan Jakarta adalah "3".

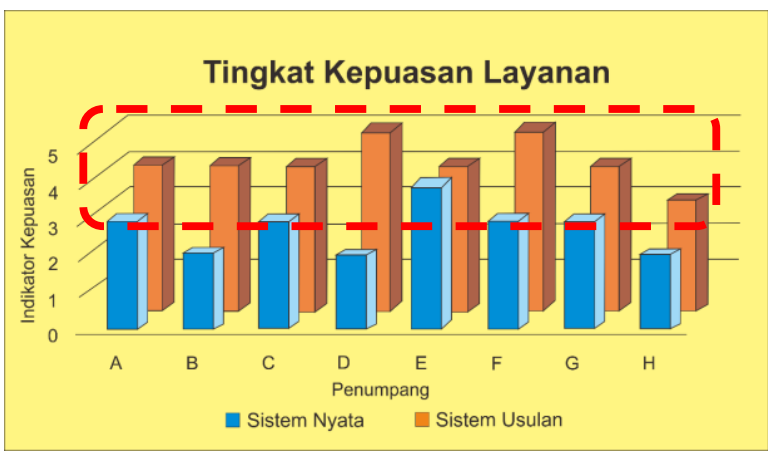

Gambar 9. Uji kepuasan pelanggan

Gambar 9 adalah grafik hasil komparasi dari tingkat kepuasan pelanggan 0-5 yang penulis lakukan pada 8 penumpang kereta api yang ada di Stasiun Gubeng Lama Surabaya dalam bentuk kuisioner. Dengan hasil 7 orang dari 8 penumpang memberikan penilaian kepuasan terhadap sistem usulan dan dapat membawa sistem lebih efisien serta memberikan kenyamanan kepada para penumpang kereta api.

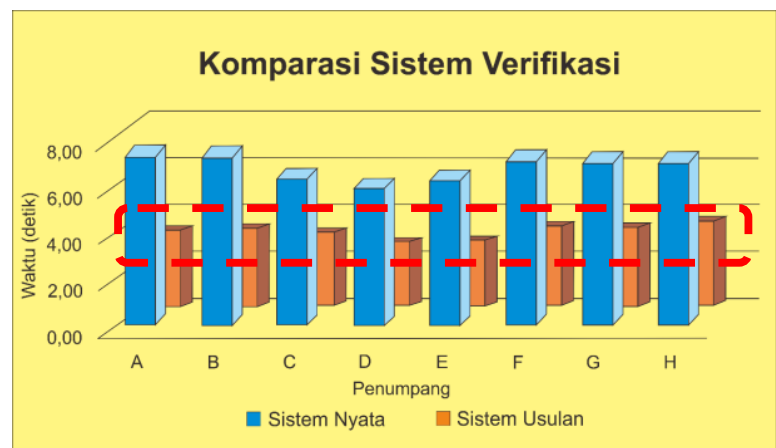

Gambar 10. Uji efisiensi waktu

Pada Gambar 10 menampilkan grafik yang menjelaskan waktu 8 penumpang untuk sampai pada kursi yang sudah dipesan sesuai tiket menggunakan stopwatch. Dimana waktu dari 8 penumpang tersebut telah penulis komparasi dengan sistem usulan dengan cara menyalakan sistem verifikasi barcode yang sudah dibuat lalu didapatkan hasil perhitungan waktu seperti grafik pada Gambar 10.

Tabel 1. Uji efisiensi waktu

\begin{tabular}{cccc}
\hline $\begin{array}{c}\text { Sistem Usulan } \\
\text { (s) }\end{array}$ & $\begin{array}{c}\text { Sistem Nyata } \\
\text { (s) }\end{array}$ & Penumpang & Efisiensi \\
\hline 3.2 & 6.5 & $\mathrm{~A}$ & $49 \%$ \\
3.3 & 6.5 & $\mathrm{~B}$ & $51 \%$ \\
3 & 5.8 & $\mathrm{C}$ & $52 \%$ \\
2.2 & 5 & $\mathrm{D}$ & $44 \%$ \\
2.25 & 5.1 & $\mathrm{E}$ & $44 \%$ \\
3.4 & 6.3 & $\mathrm{~F}$ & $54 \%$ \\
3.3 & 6.1 & $\mathrm{G}$ & $54 \%$ \\
3.5 & 6.1 & $\mathrm{H}$ & $57 \%$ \\
\hline
\end{tabular}

Dari Table 1, diperoleh bahwa sistem usulan $51 \%$ lebih efisien ketimbang sistem nyata yang ada.

\section{PENUTUP}

Cara kerja sistem electric smart chair yaitu dengan sistem scanning barcode yang terletak pada gerbong kereta api di sebelah kamar mandi. Sehingga penumpang langsung bisa mengecek tiket yang telah dipesan dan duduk ditempat sesuai dengan nomor bangku yang dipesan pada tiket.

Prinsip kerja electric smart chair dengan mengkombinasikan beberapa perangkat keras dan perangkat lunak. Mulai dari pemesanan dan percetakan tiket penumpang dilakukan menggunakna software DELPHI. Selanjutnya penumpang diwajibkan melakukan proses verifikasi scanning barcode. Database yang telah di scanning akan memerintahkan motor servo untuk bergerak membuka kursi penumpang dan terdapat 
indikator warna lampu hijau di bagian samping kursi.

Desain sistem yang dibuat terdapat scanning barcode yang terletak pada ujung depan dan belakang setiap gerbong kereta api. Sehingga memungkinkan untuk setiap penumpang melakukan proses verifikasi dengan cepat dan tidak terjadinya antrian penumpang yang panjang.

\section{DAFTAR PUSTAKA}

Agmasari, S. (2016). Hati-hati, Jelang Mudik Bukan Calo yang Beredar di Stasiun, tapi... Retrieved January 1, 2018, from https://travel.kompas.com/read/2016/05/ 24/210400327/hatihati.jelang.mudik.bukan.calo.yang.beredar.di .stasiun.tapi..

Agustina, S., \& Nugroho, N. (2015). ANALISA MOTOR DC (DIRECT CURRENT) SEBAGAI PENGGERAK MOBIL LISTRIK. Jurnal Mikrotiga, 2(1).

Juliyanto, I. T. (2015). Strategi Peningkatan Kualitas Pelayanan Jasa Transportasi Kereta Api (Studi Pada PT. Kereta Api Indonesia (Persero) Dearah Operasi VII Madiun). Jurnal Administrasi Publik, 3(1), 118-121.
Plaza, J., \& Abu, M. (2015). Sistem Informasi Perpustakaan Di SMP Negeri 12 Kotabumi Berbasis Borland Delphi 7. Jurnal Informatika Darmajaya, 15(2), 102-115.

Puspawardhana, N., Suhartati, F., \& Nurwati, T. (2014). Pengaturan Posisi Motor Servo Pada Miniatur Rotary Parking. Jurnal Mahasiswa TEUB, 2(5).

Rahayu, C. M. (2017). Evakuasi Selesai, Relasi KRL Jabodetabek Kembali Normal. Retrieved January 1, 2018, from https://news.detik.com/berita/d3668373/evakuasi-selesai-relasi-krljabodetabek-kembali-normal

Shukla, J. R. D. A. P. R. M. (2015). Barcode Scanner. International of Engineering Technology \& Management Research, 3(1), 118-121.

Sjafruddin, A., Sadono, M., Ridwan, A. S., Tamin, 0. Z., Ismanto, B., Widodo, P., ... Karsaman, R. H. (2006). TANTANGAN DAN PEMECAHAN MASALAH SEKTOR TRANSPORTASI DI INDONESIA. Status, Prospek, Dan Permasalahan Ipteks Menjelang Abad Ke-21, 32(2), 89-123. 
S W Priyadi, dkk / Teknika : Engineering and Sains Journal, Vol. 2, No.2, Desember 2018, 125-130

Halaman ini sengaja dikosongkan 